\title{
Biomarkers in Rock Oysters (Saccostrea mordax) in Response to Organophosphate Pesticides
}

\author{
Kennedy Opiyo ${ }^{1}$, Chris Rawson ${ }^{1}$, Marthe M. Gagnon ${ }^{1}$, Ishaaq Saputra ${ }^{1,2 *}$ \\ ${ }^{1}$ School of Molecular and Life Sciences, Curtin University, Australia \\ Kent Street, Bentley, Western Australia 6102 Australia \\ 2 Fish Quarantine and Inspection Agency Regional Office Jakarta I \\ Agriculture Quarantine Building, Soekarno-Hatta International Airport, Tangerang 15126 Indonesia \\ Email: ishaaq.saputra@student.curtin.edu.au
}

\begin{abstract}
Chlorpyrifos is a xenobiotics contaminants that threats the marine environment and the living organism within the habitat. Although several marine bivalve species have been used as the indicator of marine pollution, the used of Saccostrea mordax is remaining unknown. This study aimed at investigating the suitability of lysosome membrane integrity, carboxylesterase activity, 8-oxo-2'-deoxyguanosine and condition index as biomarkers in adult S. mordax following their exposure to 0.0, 5.0 and $500 \mu \mathrm{g} . \mathrm{L}^{-1}$ of Chlorpyrifos for 21 days under laboratory conditions. Results indicated that the lysosome membrane integrity showed a dose-dependent response with a significant statistical number of destabilized cells between all the treatment groups. Carboxylesterase activity was significantly inhibited in $500 \mu g . L^{-1}$ chlorpyrifos treated group, while the environmentally relevant concentration (5 $\left.\mu g . L^{-1}\right)$ did not induce a significant inhibition with reference to the control. Similarly, the condition index showed a dose-dependent response with the oysters exposed to $500 \mu \mathrm{g} \cdot \mathrm{L}^{-1}$ chlorpyrifos exhibiting a significantly reduced growth rate. There was no statistical significance in the means of both 8-oxo-2'-deoxyguanosine in all treatment groups. The reaction of S. mordax to chlorpyrifos contamination demonstrates that the species can potentially be used as sentinel organisms in environmental monitoring programs. Lysosome membrane integrity was a single out as a sensitive biomarker for exposure to chlorpyrifos and is therefore suitable for environmental monitoring for sublethal concentrations of chlorpyrifos contaminations. Additionally, the use of multiple biomarkers was found to be robust in this study and can be extrapolated to other ecotoxicological studies
\end{abstract}

Keywords: biomarkers, chlorpyrifos, oyster, S. mordax, pesticides

\section{Introduction}

Aquatic environments are becoming more stressed from xenobiotic contaminants. These contaminants from point and diffuse agricultural, residential and Industrial sources, are deposited into littoral areas through spray drifts and run-offs (Tedoldi et al., 2016). The expansion of modern agriculture has resulted to the use of high concentration of agrochemicals such as pesticides (Insecticides, fungicides, herbicides, fumigants and rodenticides) and fertilizers (Lappharat et al., 2014; Patetsini et al., 2013) which coupled with natural stressors from climate change have increased vulnerability of aquatic ecosystems to pollution. Although more stringent regulations on formulations and advocacy on moderated use of pesticides are in (Osteen and Fernandez-Cornejo, 2013), trends indicate increased application of pesticides (Liu et al., 2015). Consequently, causing poisoning, death, carcinogenesis, stress, endocrine disruption and upset of population size and distribution of fish. Thus raises concerns on the health integrity of the aquatic ecosystems (Patetsini et al., 2013). One of the commonly used pesticides albeit associated with ecological effects is chlorpyrifos. Chlorpyrifos is effectively used as a broad-spectrum chlorinated organophosphate pesticide to control insects, termites, acaroid and nematodes in homes, agriculture and golf courses. Its use has been extensively documented following its introduction to the market in 1965 (Eaton et al., 2008). Although the exposure and contamination of chlorpyrifos from households have reduced following its restriction, particularly in the US and EU, its widespread application in agriculture has escalated to unprecedented levels (Eaton et al., 2008). For instance, in 1990, about $635.000 \mathrm{~kg}$ of chlorpyrifos was used in Central Valley of California (Bailey et al., 1997) while in 1997, about 6 million kg were used in the US (Gilliom et al., 2006). Chlorpyrifos remains the main pesticide applied in agriculture in Argentina; approximately 3 million liters of chlorpyrifos was used in 2012 (Martinez et al., 2015). 
The various pathways through which organophosphate pesticides become bioavailable in the aquatic systems complicate their biochemical reactions. Previous studies indicate the obliquity of biochemical pathway of organophosphate pesticides with regards to non-target species. For example, Canesi et al. (2011) in a study with marine mussels conclude that chlorpyrifos caused endocrine disruption of natural estrogen, subsequently impairing the uptake of $\mathrm{Ca}^{2+}$ and metabolic processes. Besides, the extent of influence of natural stressors on the biochemical reactions of organophosphates has never been exhaustively demystified (Relyea and Hoverman, 2006). There is no single biomarker that is robust enough to diagnose environmental contamination. The current trend in ecotoxicology is the use of a battery of biomarkers that provide early-warning signs of environmental contamination, thus, enable appropriate diagnostic, prognostic and intervention tools which are geared towards sound environmental best practices and environmental risk assessments. Although chemical analyses can be used to detect the presence of a contaminant in aquatic system, they do not assess the impacts of such contaminants on aquatic organism, therefore, the suitability of biomarkers (Sarkar et al., 2006). Some studies have indicated that bioaccumulation of organophosphate pesticides in marine gastropods initiate different physiopathological processes that include the elevation of the generation of reactive oxygen species (ROS). ROS are products from partial reduction of molecular oxygen in the cells arising from biochemical process in an organism (Lushchak, 2011). Although some ROS such as peroxides $\left(\mathrm{H}_{2} \mathrm{O}_{2}\right)$, hydroxyl $\left(\mathrm{OH}^{-}\right)$and superoxide $\left(\mathrm{O}_{2}\right)$ are naturally produced in the mitochondria and endoplasmic reticulum, such ROS are controlled through a counter-reaction with antioxidant enzymes such as catalases and antioxidants. However, exposure to contaminants induces overproduction of ROS which diffuse through biological membranes and cause damages in places far from their origins, resulting into oxidative stress (Oliveira et al., 2010).

Oysters have been used in ecotoxicological studies to deduce both temporal and spatial contaminations in aquatic environments (Domouhtsidou et al., 2004; Edge et al., 2012). They feed through filtration of the water column, thereby enhancing light penetration. Oysters accumulate contaminants through body surfaces and feeding. In addition, oysters are sessile hence are ideal for site exposure studies. The contaminants are often at a higher concentration than in the surrounding medium, essentially making them ideal for ecotoxicological studies (Moreira et al., 2013). The marine pollution have been evaluated using biomarkers features in some marine bivalves.
However, the use of Saccrostrea mordax is still unknown. The aim of the present study is to investigate the use of 8-oxo-gd, carboxylesterase activity, lysosomal membrane integrity and condition factor in $S$. mordax as a biomarker of the environmental contamination with chlorpyrifos.

\section{Materials and Methods}

\section{Chemicals}

The organophosphate insecticide used was commercial-grade formulation (Chlorpyrifos 500EC insecticide; active constituent: 500 g. $\mathrm{L}^{-1}$ chlorpyrifos; in 480 g. $\mathrm{L}^{-1}$ in liquid hydrocarbon solvent) purchased from Nufarm Australia Limited, Western Australia. Other chemicals used were of high purity levels and unless stated, they were obtained from SigmaAldrich, Australia.

\section{Animals}

Since oysters have no specific size, the present study will use the average wet weight of Saccostrea mordax. A total number of 36 of $S$. mordax $(60.775 \pm$ $17.091 \mathrm{~g}$ ) were harvested from oyster reef in Kalbarri, Western Australia. This site was particularly chosen due to its isolation from agricultural activities hence less likelihood of organophosphate contamination. The oysters were transported in moist eskies to Curtin Aquaculture Research Laboratory in Bentley, Western Australia. The oysters were acclimated for 10 days in $20 \mathrm{~L}$ water (Salinity of $35 \mathrm{ppt} ; 26^{\circ} \mathrm{C}$ ) and were fed on a commercial product of known as shellfish diet 1800 (instant algae) composed of concentrates of six marine microalgae species (40\% Isochrysis galbana) at a rate of $7.0 \times 10^{6}$ cells $\mathrm{mL}^{-1}$ every $24 \mathrm{~h}$, for the acclimation and the exposure periods. Half of the water in the holding tanks was changed after every $36 \mathrm{~h}$.

\section{Exposure of the oysters}

A set of 36 aquaria of a capacity of $1 \mathrm{~L}$ were used in this experiment. The set was sub-divided into 3 subsets, each containing 12 aquaria designated for

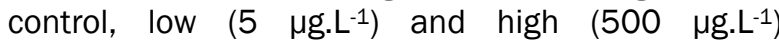
concentration treatments. The aquaria were randomly placed in a large water bath whose temperature was maintained at $26^{\circ} \mathrm{C}$. Each aquarium had 2 oysters that had been randomly sampled from the original batch. Air was gently bubbled through each aquarium for the entire exposure period. The oysters were exposed to 14 and $10 \mathrm{~h}$ of light and darkness respectively, for a period of 21 days. The ambient conditions were maintained as follows; temperature $24.799 \pm 0.729^{\circ} \mathrm{C}$, percentage dissolved oxygen $82.173 \pm 0.402 \%$, dissolved oxygen 
$5.593 \pm 0.026 \mathrm{mgL}^{-1}$, salinity $33.374 \pm 0.094 \mathrm{ppt}$ and $\mathrm{pH}$ of $7.156 \pm 0.026$. The whole of the water in the aquaria was being change after every $36 \mathrm{~h}$.

\section{Sample preparations}

After the exposure period, the whole weight and the wet weight and the shell weight were measured to the nearest 0.001 using analytical weighing scale and all the measured parameters were recorded for working condition index. The shells were opened using oysters knife. The digestive glands of 12 individuals from a subset were each carefully excised and immediately analysed for lysosome membrane integrity. The digestive glands of the rest of the exposed oysters were individually excised, divided into 2 parts and immediately refrigerated at $-85^{\circ} \mathrm{C}$ for later biochemical analyses.

\section{Determination condition index and lysosomal membrane integrity}

Condition index was determined according to Filgueira et al. (2013) with following equations: $\mathrm{Cl}=$ wet weight/(whole weight-shell weight) $\times 100$. The lysosomal membrane integrity assay was conducted according to the procedure adopted from Ringwood et al. (1998). Fresh tissues of the digestive gland $(0.02 \mathrm{~g})$ were rinsed in calcium- and magnesium-free saline (CMFS contained $20 \mathrm{mM}$ HEPES, $480 \mathrm{mM}$ $\mathrm{NaCl}, 12.5 \mathrm{mM} \mathrm{KCl}$, and $5.0 \mathrm{mM} \mathrm{CaCl}_{2}$, $\mathrm{pH}$ adjusted to 7.4 using $6 \mathrm{~N} \mathrm{NaOH}$ ), minced and rinsed again, and transferred into microcentrifuge tubes kept in ice. The tissues were disintegrated and cells dissociated through the addition of CMFS followed by gentle shaking on reciprocating shaker at $120 \mathrm{rpm}$ for 20 mins Further cellular dissociation was achieved through the addition of trypsin at pH 7.4, followed by shaking on a reciprocating shaker at $120 \mathrm{rpm}$ for 20 mins. The mixture was sheared before filtration through a $23 \mu \mathrm{m}$ screen. The filtrate was centrifuged at $300 \mathrm{~g}$ for 5 mins. The supernatant was discarded and the cells were resuspended in $1 \mathrm{ml} \mathrm{CMFS}$ and again centrifuged $300 \mathrm{~g}$ for 5 mins. Finally, the cell resuspended in $900 \mu \mathrm{l}$ of CMFS and mixed with freshly prepared neutral red (Secondary solution of NR of $0.08 \mathrm{mg} / \mathrm{ml}$ dissolved in CMFS) at 9:1 respectively. The dyed cell suspension was incubated for $1 \mathrm{~h}$ at room temperature before observed under $40 X$ objective lens with a total magnification of $400 x$. The scores were recorded for 50 cells. Based on the dye retention ability, the cells with dye enclosed in the lysosomes were classified as stable while the ones in which the dye oozed into the cytosol were considered destabilised. The percentage of destabilised cells were then calculated by dividing the number of cells with the dye in the cytosol with the total number of cells counted then multiplied by 100 .

\section{Determination of Carboxylesterase Activities}

The carboxylesterase activity in the digestive gland of each oyster $(n=12)$ was analysed using 1Naphthyl acetate as a substrate as adopted by Baker et al. (2016). The digestive system which had been kept at $-85^{\circ} \mathrm{C}$ was slowly thawed in ice, weighed and homogenised in $0.02 \mathrm{M}$ phosphate buffer solution (with $1 \%$ triton $\mathrm{X}-100, \mathrm{pH} 8.0$ )) at a ratio of 1unit weight of the sample to 3.5unit volume of the homogenisation buffer. The homogenate was pipetted into a $5 \mathrm{ml}$ glass tube and diluted with $0.2 \mathrm{M}$ homogenisation buffer solution (devoid of triton X100 ) at volume ratio of 1:20 respectively, and the resulting solution centrifuged at $14,000 \mathrm{~g}$ for 4 mins at $4^{\circ} \mathrm{C}$. The resulting supernatant was further diluted with $0.2 \mathrm{M}$ homogenisation buffer solution (devoid of triton $\mathrm{X}-100$ ) at 1:4 respectively. Twenty $\mathrm{mL}$ of $0.2 \mathrm{M}$ homogenisation buffer solution was pipetted into blank on the microplate, $20 \mu \mathrm{l}$ of the diluted supernatant was pipetted into microplate in triplicate in specific plate layout, followed by addition of $190 \mu \mathrm{l}$ assay buffer (50mg of Fast Blue RR salt dissolved in $25 \mathrm{ml}$ freshly prepared $0.2 \mathrm{M}$ homogenisation buffer, devoid of triton X-100, diluted in $500 \mu \mathrm{l}$ 1-Naphthyl acetate stock solution) to the wells of the microplate. The increase in absorbance was carried out for each minute for 10 mins at $450 \mathrm{~nm}$ and $25^{\circ} \mathrm{C}$ using microplate reader. The proteins content was analysed by Bradford assay (Bradford, 1976) using bovine globulin solution as a standard, and read on microplate at $595 \mathrm{~nm}$. The values were entered into excel and the final results were compared to the

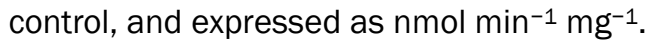

\section{DNA Extraction and Quantification of 8-oxo-dG}

The DNA extraction was conducted according to spin-column protocol as outlined in a commercially available kit (QIAGEN, 2006). Briefly, the previously refrigerated digestive tissues were slowly thawed in ice. Tissues $(0.025 \mathrm{~g}$ ) were sliced out and placed into $1.5 \mathrm{ml}$ tubes followed by addition of buffer ATL and proteinase $\mathrm{K}$ to lyse the tissue and digest proteins respectively. The mixture was thoroughly vortexed and incubated at $56^{\circ} \mathrm{C}$ with occasional vortexing. Further lysis of cells and membranes was achieved through the addition of buffer AL and the DNA precipitated through addition of absolute ethanol. The mixture was transferred into spin column and centrifuged at $6000 \mathrm{~g}$. The debris in the spin column was washed using Buffers AW1 following centrifugation for 1 minute at $6000 \mathrm{~g}$. Further washing was achieved through addition of buffer AW2 following centrifugation for 3 mins at $13500 \mathrm{~g}$. Finally, $100 \mu$ l buffer AE was used to elute DNA from the filter in the spin column at centrifugation speed of $6000 \mathrm{~g}$ for $1 \mathrm{~min}$. The DNA material was then quantified using thermos scientific NanoDrop 2000 
spectrophotometer. The unwinding and deploymerisation of the collected DNA materials were achieved through the addition of DNase 1 and alkaline phosphatase respectively into the samples.

The DNA materials were quantified using a commercial enzyme-like immunosorbent assay (ELISA) kit (Trevigen, 2015). Briefly, $25 \mu$ of 8-oxo-dG standard (diluted with Assay Diluent) and another 25 $\mu$ I DNA samples were added to appropriate wells on a 96 pre-coated wells plate in duplicates. Assay Diluent was added to the blanks as control, followed by addition of $25 \mu \mathrm{l}$ Anti-OHdG monoclonal solution. The plate was covered with film sealer and incubated for $1 \mathrm{~h}$ at $25^{\circ} \mathrm{C}$. Following incubation, plate was washed 4 times with phosphate-buffered saline tween (PBS and 1\% Tween 20) using immunowash model 1575 (Bio-Rad Laboratories Pty Ltd, NSW, Australia). Twenty-five microlitres of Goat anti-mouse IgG-HRP conjugate was added to each well, with the exception of the blanks, and the mixture again incubated for $1 \mathrm{hr}$ at $25^{\circ} \mathrm{C}$. The wells were washed using PBST as before, followed by the addition of $50 \mu$ TACSSapphire colorimetric substrate which had been prewarmed to room temperature. The plate was then incubated in the dark for 15 minute at room temperature. The reaction was stopped by with $0.2 \mathrm{M}$ $\mathrm{HCl}$ and the plate was immediately read using a BioRad iMark Microplate Reader through an absorbance of $450 \mathrm{~nm}$. The microplate readings were used to calculated the 8-oxo-dg concentration using the worksheet provided on Trevigen website using MS excel.

\section{Data analysis}

Normality of distribution and homogeneity of variance was analysed by Kolmogorov-Smirnoff and Levene tests respectively. The data for all the assays conformed to Normality of distribution and homogeneity of variance. The significance level was fixed at $\alpha=0.05$. Significant difference between means was analysed with one-way ANOVA for all the assays and Tukey's HSD test was subsequently used to compare the variations between treatment groups. Statistical analysis was performed using SPSS v. 23.

\section{Result and Discussion}

The condition index, lysosome membrane integrity, carboxylesterase activity, 8-oxo-2'deoxyguanosine can be used as biomarkers in adult rock oyster (S. mordax). The exposure of chlorpyrifos pesticide at low and high concentration affect the lysosome membrane integrity and carboxylesterase activity. Condition indices in bivalves occur at organismal level thus are considered as late signal of stress, however, they have been used in ecotoxicological experiments as markers of chronic contamination. In the present study, there was no significant difference $\left(\mathrm{F}_{2,33}=0.458 \mathrm{p}=0.636\right)$ in condition index of $S$. mordax between the control and the treatment groups. The condition index of low and high treatments were $37.16 \pm 1.59$ and $38.57 \pm$ 1.91, respectively (Figure 1.). Generally, studies have indicated that condition index is a reliable biomarker of contamination in bivalves (Smith and Reddy, 2012). For instance, Benali et al. (2015) demonstrated dose-dependent response in condition index of M. galloprovincialis in a field study. However, the lack of significant difference in condition index between the treatment groups in the current study may be explained by the fact that condition index is a late signal of stress which occur at organismal level following the damages at cellular and sub-cellular levels due to exposure to a contaminant. additionally, oysters are known to compensate for the weight loss of energy-storage structures with water (Lucas and Beninger, 1985). This phenomenon makes it difficult to detect change in weights even in cases where such changes occur. Similar findings have been shown in previous studies with other bivalves. For instance, common mussels $(M$. edulis) shown insignificant differences in their conditions in separate field studies of contamination with tributyltin and organochloride compounds. On the contrary, a field study on $C$. virginica indicated a greater response to salinity rather that the presences and concentrations of xenobiotic contaminants (Volety, 2008). Although the condition index is potentially useful as a biomarker in $S$. mordax, it should be coupled with other biomarkers in order to ensure a robust ecotoxicological study.

Several lines of evidence from studies have indicated that lysosome membrane integrity is adversely affected following exposures to xenobiotic contaminants. However, there is no particular pathway through which contaminants affect lysosomes. Results indicated that there was a significant difference in lysosome membrane integrity between all treatment groups $\left(F_{2,30}=50.319 p<\right.$ 0.001) (Figure 2.). S. mordax exposed chlorpyrifos at high level resulted on the highest lysosomal integrity. Further both low and high chlorpyrifos exposure have also significantly higher lysosome membrane integrity than control. In the present study, the background level of destabilisation was above the $30 \%$ designated as a normal background lysosomal instability in oysters (Ringwood et al., 2005). It is probable that the reproductive cycle (spawning) elevated the normal background levels of lysosome destabilisation in this study given that the study coincided with the spawning period of $S$. mordax. 
This observation is consistent with previous study which indicated that lysosome membrane integrity in marine bivalves were adversely affected as a result of physiochemical changes that accompany spawning Cho and Jeong (2005). The results of this study demonstrated that chlorpyrifos, even in low concentrations, adversely affects the lysosome membrane integrity of $S$. mordax. Although our low concentration (5 $\mu g . \mathrm{L}^{-1}$ of Chlorpyrifos) was higher than that used by Patetsini et al. (2013) it was below agricultural concentrations of $26.6 \mu \mathrm{g} . \mathrm{L}^{-1}$ as reported by Otieno et al. (2012). Therefore, our finding justifies the regulation of the use of Chlorpyrifos in Agriculture given that a lot of agricultural activities occur in areas likely to be eroded through run-offs to aquatic system hence the possibility of affecting oysters.
In the current study, lysosomes showed high sensitivity to chlorpyrifos and the membrane destabilisation correspondingly increased with contamination gradient. This finding agrees with previous study in which chlorpyrifos induced adverse effects on the lysosome membranes of haemocytes in Mylitus galloprovicialis (Patetsini et al., 2013). The sensitivity of lysosome membrane integrity as a broad-based biomarker of stressors is further supported by several lines of evidence from both field and laboratory studies of aquatic animals (Moore et al., 2006; Webb, 2011). In a study of S. glomerata in Homebush Bay and Port Kembla in Australia, Edge et al. (2012) indicated that the lysosome membranes were destabilised following exposure to metals and poly aromatic hydrocarbons (PAH). Further evidence has been recorded in $M$. galloprovincialis exposed to

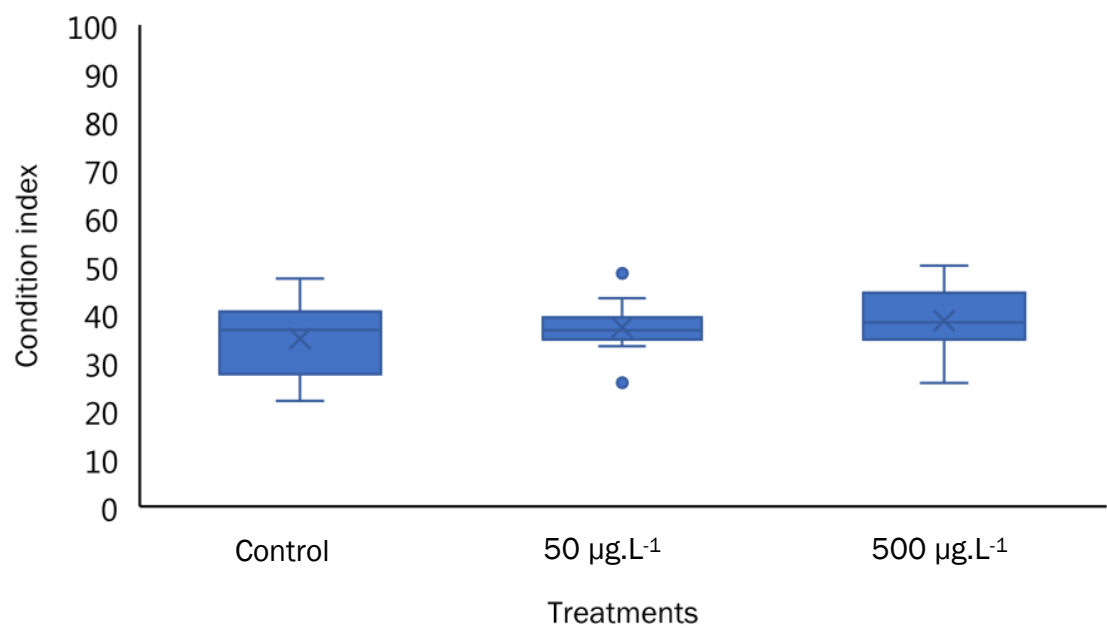

Figure 1. Condition index of $S$. modax exposed to 0,5 and $500 \mu g . L^{-1}$ of chlorpyrifos for a 21 days. There was no significant differences in the means of condition index of oyster ( $P>0.05)$

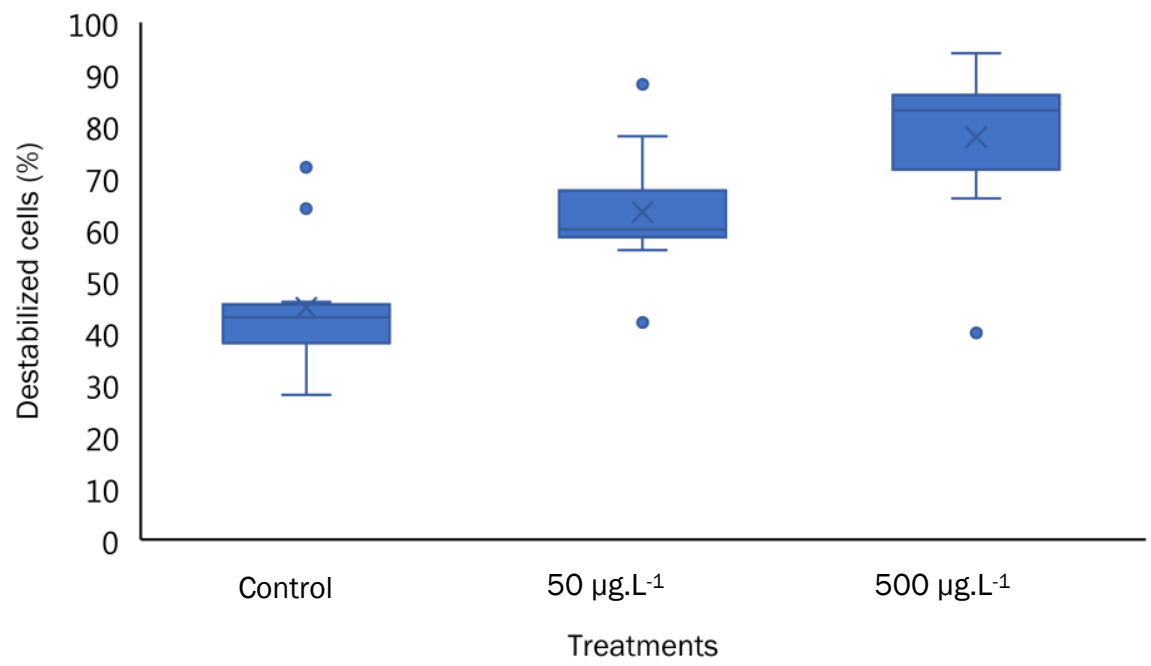

Figure 2. Percentage of cells with destabilized lysosome membranes in S. mordax exposed with treatment levels of chlorpyrifos. Group treated to high concentration of chlorpyrifos had a significantly higher destabilized cells $(p<0.05)$. 
Table 1. The condition index, lysosome membrane integrity, carboxylesterase activity and DNA damage of $S$. mordax after chlorpyrifos exposure at two levels. Value with different supercript $(a, b)$ in the similar column represent significant difference at $P<0.05$.

\begin{tabular}{lcccc}
\hline Treatments & Condition Index & $\begin{array}{c}\text { Lysosome Membrane } \\
\text { Integrity }\end{array}$ & Carboxylesterase Activity & DNA Damage \\
\hline Control & $34.87 \pm 2.40^{\mathrm{a}}$ & $44.83 \pm 3.46^{\mathrm{a}}$ & $86.59 \pm 10.53^{\mathrm{a}}$ & $27.45 \pm 3.28^{\mathrm{a}}$ \\
$5 \mu \mathrm{\mu g}$ L-1 $^{-1}$ & $37.16 \pm 1.59^{\mathrm{a}}$ & $63.33 \pm 3.29^{\mathrm{b}}$ & $73.64 \pm 7.22^{\mathrm{a}}$ & $20.51 \pm 1.90^{\mathrm{a}}$ \\
$500 \mu$ g.L.-1 $^{\mathrm{a}}$ & $38.57 \pm 1.91^{\mathrm{a}}$ & $77.83 \pm 4.15^{\mathrm{b}}$ & $34.23 \pm 6.08^{\mathrm{b}}$ & $21.10 \pm 3.92^{\mathrm{a}}$ \\
\hline
\end{tabular}

trace metal contamination (Domouhtsidou et al., 2004) and in $M$. edulis exposed to 3-Methylcholanthrene (Moore et al., 2006). A general consensus can be drawn that lysosome membrane integrity in a powerful biomarker of anthropogenic stressors in many organisms. Based on the sensitivity of lysosome membrane integrity, this study indicates that $S$. mordax is a potential sentinel particularly in areas of Australia and New Zealand where this species is endemic.

The in vivo inhibition of carboxylesterase, is an indication of the general endowment of an individual organism/species against ester-containing compounds (e.g. organophosphates), and further reflects the sensitivity of the organism to the organophosphate compounds. A significance difference was detected in the specific activity between the treatment groups $\left(F_{2,32}=12.238\right.$, $\mathrm{P}<0.001)$. There was a significantly lower specific activity (umol. $\mathrm{min}^{-1} \cdot \mathrm{mg}^{-1}$ protein) of carboxylesterase in oysters exposed to high concentration treatment than those exposed to a low concentration and control. Specific activity (umol. $\mathrm{min}^{-1} \cdot \mathrm{mg}^{-1}$ protein) of carboxylesterase was not significantly different in groups treated to low concentration of chlorpyrifos and the control (Figure 3.). The relative insensitivity of carboxylesterase activity in $S$. mordax to chlorpyrifos except to high (500 $\left.\mu \mathrm{g} . \mathrm{L}^{-1}\right)$ concentration in this study made it challenging to draw clear conclusion over the suitability of carboxylesterase as a biomarker of exposure to chlorpyrifos in the natural environment. Unfortunately, this study did not investigate a doseresponse relationship over a wide range of chlorpyrifos contamination with regards to carboxylesterase activity, therefore, it was difficult to tell whether statistically significant specific activity of carboxylesterase could be induced by environmentally relevant chlorpyrifos concentrations above $5 \mu \mathrm{g} . \mathrm{L}^{-1}$ already reported by Otieno et al. (2012). In contrast, other studies have revealed that concentrations below or equal to $5 \mu \mathrm{g} . \mathrm{L}^{-1}$ induced inhibition of carboxylesterase activities in other organisms. Rivadeneira et al. (2013) indicated that 5 $\mu \mathrm{g} . \mathrm{L}^{-1}$ of Chlorpyrifos significantly inhibited carboxylesterase in snail (Planorbarius corneus) while Wheelock et al. (2005) found a significant inhibition of carboxylesterase in chinook salmon
(Oncorhynchus Tshawytscha) upon exposure to 1.2 $\mu \mathrm{g} . \mathrm{L}^{-1}$ Chlorpyrifos. Therefore, the future of investigations should use a range of chlorpyrifos concentration to gauge the sensitivity of carboxylesterase as a potential biomarker in $S$. mordax.

Oxidative DNA damage from ROS in the cells often results into generation of 8-oxo-dG in the cells. The ROS are often induced by the presence of xenobiotic stressors such as chlorpyrifos. The DNA damage manifested as 8-oxo-dG following the exposure of organisms to chlorpyrifos, often results from the induction of ROS by Chlorpyrifos as evidenced in some studies (Rosen, 1997; Cacciatore et al., 2015; Chauhan et al., 2016). Analysis of variance test did not detect any significant differences $\left(F_{2,10}=0.095, p=0.910\right)$ in the levels of 8 Oxo-dG between the treatment groups in $S$. mordax (Figure 4.). Previous study have shown that chlorpyrifos causes DNA damage in a concentrationdependent fashion (Ali et al., 2009). However, in the present study, there was no significance difference in the amount of 8-oxo-dG between the treatment groups. On the contrary, DNA damage as a result of exposure to low concentrations of chlorpyrifos has been recorded in freshwater fish (Channa punctatus) (Ali et al., 2009). The findings of (Ali et al., 2009) has been reaffirmed in a recent study of genotoxicity of chlorpyrifos to zebrafish (Danio rerio) (Wang et al., 2014). Generally, the insignificance damage of the DNA illustrated in this experiment may be an indicator that oysters have better mechanisms of either neutralising chlorpyrifos or fast-tracking the repair of the damaged DNA. Our observation supports earlier observations that oysters are less responsive to organophosphate compounds (Ha Park et al., 2004). Although 8-oxo-dG has been well studied in human medicine, its use in ecotoxicology with reference to exposure to bivalves is limited. Based on the available literatures, it is the first time that 8-oxo-dG is studied as a potential biomarker of exposure to chlorpyrifos in oysters. Furthermore, the concentrations of chlorpyrifos used in this study are within ranges that have been recorded in the natural environment therefore, this study offers a base and a reference for future studies of genotoxicity of chlorpyrifos in oysters. 


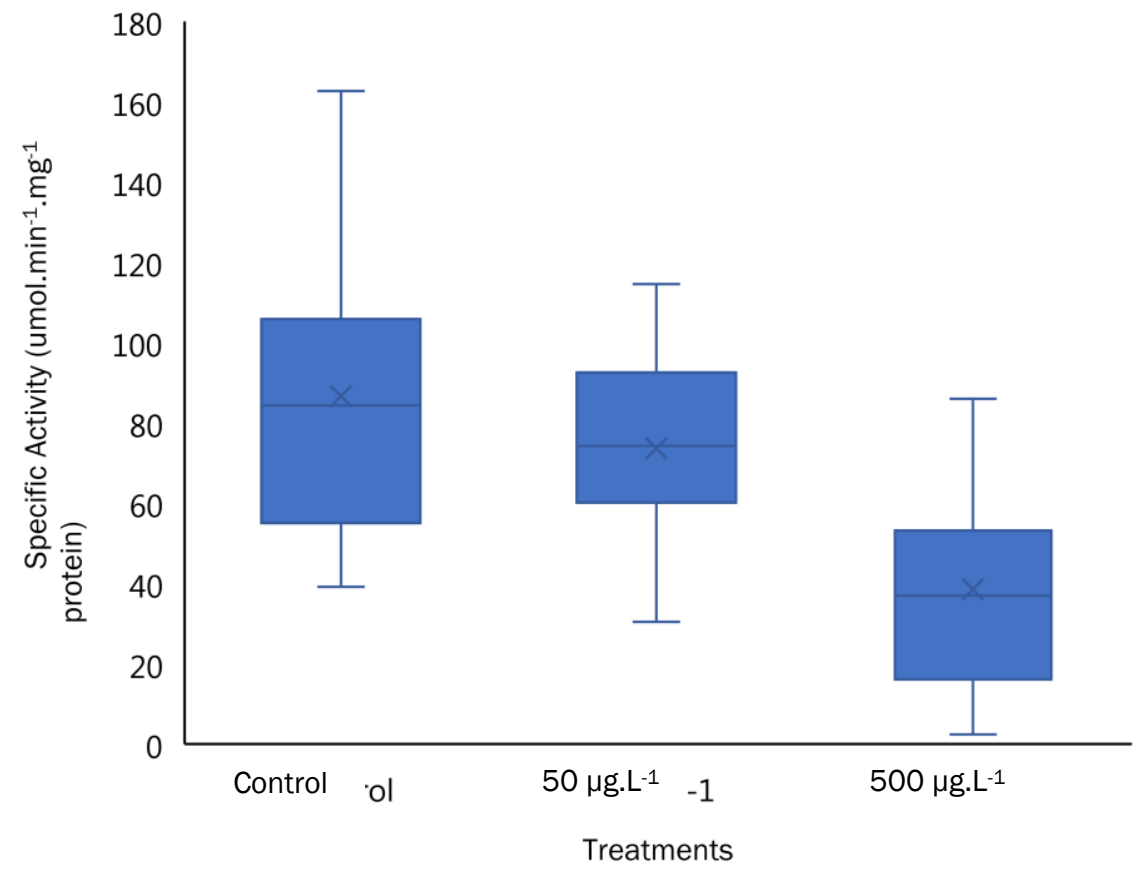

Figure 3. Specific activity (umol.min-1.mg-1 protein) of carboxylesterase in the digestive glands of adult $S$. mordax following exposure to 0,5 and $500 \mu \mathrm{g} . \mathrm{L}^{-1}$ concentrations of Chlorpyrifos. Group treated to high concentration of chlorpyrifos had a significantly lower specific activity $(P<0.05)$.

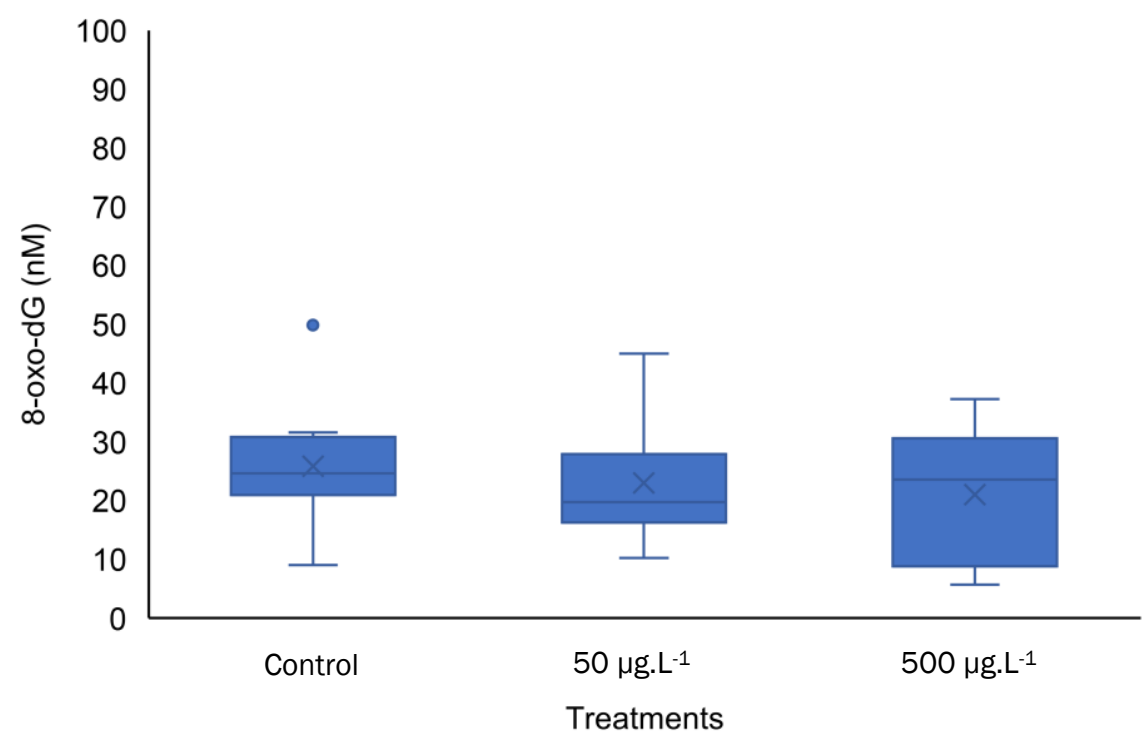

Figure 4. Amount of 8-oxo-dG in the cells of the digestive glands of $S$. mordax following exposure to Chlorpyrifos treatments. There was no significant difference between the treatment groups $(P<0.05)$.

\section{Biomarkers in chlorpyrifos regulation and monitoring}

There is no single biomarker can authoritatively be applied in environmental monitoring. As argued by Gagnon and Rawson (2016) individual biomarker does not reliably portray the true health status of an organism following contamination. Their argument supports previous assertions that although sub-organismal biomarkers particularly at molecular and cellular levels are important as early signal of contamination, they are poorly linked to effects at high biological organisations (Sarkar et al., 2006) hence they need to be looked at holistically in order to draw consistent and useful information for environmental management. In this study, lysosome membrane integrity was identified as sensitive biomarker in $S$. mordax to chlorpyrifos contamination hence can be 
applied to regulations of the pesticide as well as environmental monitoring. However, the fact that condition index and DNA materials were not significantly affected in this study is an indication of unreliable assumptions of the general health status of the oysters in case lysosome membrane integrity was looked at in isolation. In addition, following the trend in the present study that carboxylesterase activity is a potential biomarker in $S$. mordax with regards to high chlorpyrifos contaminations

\section{Conclusion}

This study indicated that the environmentally relevant concentration ( $\left.5 \mu \mathrm{g} . \mathrm{L}^{-1}\right)$ chlorpyrifos is able to adversely affect the lysosome membrane integrity of $S$. mordax in marine environment. Likewise, chlorpyrifos is able to inhibit specific activity of carboxylesterase but only in concentrations higher that $5 \mu \mathrm{g} . \mathrm{L}^{-1}$. Furthermore, the condition index of $S$. mordax would probably be affected by chronic exposure to chlorpyrifos. However, it is difficult to predict whether or not chlorpyrifos would induce DNA damage in $S$. mordax in marine environment following the exposure to chlorpyrifos. A recommendation that future investigators of 8-oxo-dG as a biomarker of DNA damage in $S$. mordax exposed chlorpyrifos should periodically measure 8-oxo-dG during and at the end of exposure in order to ascertain recovery or (lack thereof) of the NA damage. This study has equally demonstrated the necessity to utilise multiple biomarkers in ecotoxicological studies due to uniqueness in sensitivity biomarkers to a contaminant. In our case, a combination of lysosome membrane integrity, carboxylesterase activity, 8-oxo$\mathrm{dG}$ and condition index provided ecologically relevant information that can be useful in regulation and monitoring with reference to the coastlines that are inhabited by oysters.

\section{Acknowledgement}

The collection of the oysters used in the study was in accordance with Department of Fisheries license through exemption number: 2833 for the first author. Special appreciation is extended to Jarrad Baker for his assistance with collection of oysters and carboxylesterase analysis. Equally appreciated are Phillipa Adamson and Lydia Kupsky for their generous help with the laboratory work.

\section{References}

Ali, D., Nagpure, N. S., Kumar, S., Kumar, R., Kushwaha, B. \& Lakra, W. S. 2009. Assessment of genotoxic and mutagenic effects of chlorpyrifos in freshwater fish Channa punctatus (Bloch) using micronucleus assay and alkaline single-cell gel electrophoresis. Food Chem Toxicol, 47(3): 650-656. doi:10.1016/j.fct. 2008.12.021

Bailey, H. C., Miller, J. L., Miller, M. J., Wiborg, L. C., Deanovic, L. \& Shed, T. 1997. Joint acute toxicity of diazinon and chlorpyrifos to Ceriodaphnia dubia. Environ. Toxicol. Chem., 16(11): 23042308. doi: $10.1002 /$ etc.5620161115

Baker, J., Long, S., Hassell, K., Pettigrove, V. \& Gagnon, M. 2016. Health Status of Sand Flathead (Platycephalus bassensis), Inhabiting an Industrialised and Urbanised Embayment, Port Phillip Bay, Victoria as Measured by Biomarkers of Exposure and Effects. PLoS One, 11(10):p.e0164257. doi: 10.1371/journal.pone. 0164257

Benali, I., Boutiba, Z., Merabet, A. \& Chèvre, N. 2015. Integrated use of biomarkers and condition indices in mussels (Mytilus galloprovincialis) for monitoring pollution and development of biomarker index to assess the potential toxic of coastal sites. Mar. Pollut. Bull., 95(1): 385-394. doi: 10.1016/j.marpolbul.2015.03.041

Bradford, M.M. 1976. A rapid and sensitive method for the quantitation of microgram quantities of protein utilizing the principle of protein-dye binding. Anal. Biochem., 72(1): 248-254. doi: 10.1016/0003-2697(76)90527-3

Cacciatore, L.C., Nemirovsky, S.I., Verrengia Guerrero, N.R. \& Cochón, A.C. 2015. Azinphos-methyl and chlorpyrifos, alone or in a binary mixture, produce oxidative stress and lipid peroxidation in the freshwater gastropod Planorbarius corneus. Aquat. Toxicol., 167: 12-19. doi: 10.1016/j.aquatox.2015.07.009

Canesi, L., Negri, A., Barmo, C., Banni, M., Gallo, G., Viarengo, A. \& Dondero, F. 2011. The Organophosphate Chlorpyrifos Interferes with the Responses to $17 \beta$-Estradiol in the Digestive Gland of the Marine Mussel Mytilus galloprovincialis. PLOS ONE, 6(5): e19803. doi: 10.1371/journal.pone.0019803

Chauhan, L.K.S., Varshney, M., Pandey, V., Sharma, P., Verma, V.K., Kumar, P. \& Goel, S.K. 2016. ROS-dependent genotoxicity, cell cycle perturbations and apoptosis in mouse bone marrow cells exposed to formulated mixture of cypermethrin and chlorpyrifos. Mutagenesis, 31(6): 635-642. doi:10.1093/mutage/gew031

Cho, S.M. \& Jeong, W.G. 2005. Spawning impact on lysosomal stability of the Pacific Oyster, 
Crassostrea gigas. Aquaculture, 244(1-4): 383387. doi: 10.1016/j.aquaculture.2004.12.013

Domouhtsidou, G.P., Dailianis, S., Kaloyianni, M. \& Dimitriadis, V.K. 2004. Lysosomal membrane stability and metallothionein content in Mytilus galloprovincialis (L.), as biomarkers: Combination with trace metal concentrations. Mar. Pollut. Bull., 48(5-6): 572-586. doi: 10.1016/j.marpolbul.2004.01.013

Eaton, D.L., Daroff, R.B., Autrup, H., Bridges, J., Buffler, P., Costa, L.G., Coyle, J., McKhann, G., Mobley, W.C., Nadel, L., Neubert, D., SchulteHermann, R. \& Spencer, P.S. 2008. Review of the Toxicology of Chlorpyrifos With an Emphasis on Human Exposure and Neurodevelopment. Critical Rev. Toxicol., 38(S2): 1-125, doi: 10.1080/10408440802272158

Edge, K.J., Johnston, E.L., Roach, A.C. \& Ringwood, A.H. 2012. Indicators of environmental stress: cellular biomarkers and reproductive responses in the Sydney rock oyster (Saccostrea glomerata). Ecotoxicology, 21(5): 1415-1425. doi: 10.1007/s10646-012-0895-2

Filgueira, R., Comeau, L., Landry, T., Grant, J., Guyondet, T. \& Mallet, A. 2013. Bivalve condition index as an indicator of aquaculture intensity: A meta-analysis. Ecol. Indicat., 25: 215-229. doi: 10.1016/j.ecolind.2012.10.001

Gagnon, M.M. \& Rawson, C.A. 2016. Integrating Multiple Biomarkers of Fish Health: A Case Study of Fish Health in Ports. Arch. Environ. Contam. Toxicol., 70(2): 192-203. doi: 10.1007/s00244015-0258-0

Gilliom, R.J., Barbash, J.E., Crawford, C.G., Hamilton, P.A., Martin, J.D., Nakagaki, N., Nowell, L.H., Scott, J.C., Stackelberg, P.E., Thelin, G.P. \& Wolock, D.M. 2006. The quality of our Nation's waters pesticides in the Nation's streams and ground water, 1992-2001. Reston, VA: Reston, VA, United States: U. S. Geological Survey.

Ha Park, K., Kim, Y.S., Chung, E.Y., Choe, S.N. \& Choo, J.J. 2004. Cardiac responses of Pacific oyster Crassostrea gigas to agents modulating cholinergic function. Comp. Biochem. Phys. C, 139(4): 303-308. doi: 10.1016/j.cca.2004.12. 009

Lappharat, S., Siriwong, W., Taneepanichskul, N., Borjan, M., Maldonado Perez, H. \& Robson, M. 2014. Health risk assessment related to dermal exposure of chlorpyrifos: a case study of rice growing farmers in Nakhon Nayok Province,
Central Thailand. J. Agromed., 19(3): 294-302. doi:10.1080/1059924X.2014.916643

Liu, Y., Pan, X. \& Li, J. 2015. A 1961-2010 record of fertilizer use, pesticide application and cereal yields: a review. Agron. Sustain. Dev., 35(1): 8393. doi: 10.1007/s13593-014-0259-9

Lucas, A. \& Beninger, P.G. 1985. The use of physiological condition indices in marine bivalve aquaculture. Aquaculture, 44(3): 187-200. doi: 10.1016/0044-8486(85)90243-1

Lushchak, V.I. 2011. Environmentally induced oxidative stress in aquatic animals. Aquat Toxicol, 101(1): 13-30. doi: 10.1016/j.aquatox. 2010.10.006

Martinez, R.S., Di Marzio, W.D. \& Sáenz, M.E. 2015. Genotoxic effects of commercial formulations of Chlorpyrifos and Tebuconazole on green algae. Ecotoxicology, 24(1): 45-54. doi: 10.1007/s106 46-014-1353-0

Moore, M.N., Icarus-Allen, J. \& McVeigh, A. 2006. Environmental prognostics: An integrated model supporting lysosomal stress responses as predictive biomarkers of animal health status. Mar. Environ. Res., 61(3): 278-304. doi: 10.1016/j.marenvres.2005.10.005

Moreira, F.T., Browne, M.A. \& Coleman, R.A. 2013. Effect of extraction-method, period of incubation and tidal emersion on the viability of haemocytes from oysters. Mar. Pollut. Bull., 74(1): 208-212. doi: 10.1016/j.marpolbul.2013. 06.056

Oliveira, M., Maria, V.L., Ahmad, I., Teles, M., Serafim, A., Bebianno, M.J., Pacheco, M. \& Santos, M.A. 2010. Golden grey mullet and sea bass oxidative DNA damage and clastogenic/aneugenic responses in a contaminated coastal lagoon. Ecotoxicol. Environ. Saf., 73(8): 1907-1913. doi: 10.1016/j.ecoenv.2010.07.003

Osteen, C.D. \& Fernandez-Cornejo, J. 2013. Economic and policy issues of U.S. agricultural pesticide use trends. Pest. Manage. Sci., 69(9):10011025. doi: 10.1002/ps.3529

Otieno, P O., Schramm, K.W., Pfister, G., Lalah, J.O., Ojwach, S.O. \& Virani, M. 2012. Spatial Distribution and Temporal Trend in Concentration of Carbofuran, Diazinon and Chlorpyrifos Ethyl Residues in Sediment and Water in Lake Naivasha, Kenya. Bull. Environ. Contam. Toxicol., 88(4): 526-532. doi: 10.1007 /s00128-012-0529-7 
Patetsini, E., Dimitriadis, V.K. \& Kaloyianni, M. 2013. Biomarkers in marine mussels, Mytilus galloprovincialis, exposed to environmentally relevant levels of the pesticides, chlorpyrifos and penoxsulam. Aquat. Toxicol., 126: 338-345.

QIAGEN. 2006. DNeasy Blood \& Tissue Handbook. Retrieved from https://www.qiagen.com/au/ resources/resourcedetail?id=6b09dfb8-6319464d-996c-79e8c7045a50\&lang=en

Relyea, R. \& Hoverman, J. 2006. Assessing the ecology in ecotoxicology: a review and synthesis in freshwater systems. Ecol. Lett., 9: 1157-1171

Ringwood, A.H., Conners, D.E., Hoguet, J. \& Ringwood, L.A. 2005. Techniques in Aquatic Toxicology, Chapter : Lysosomal destabilization assays for estuarine organisms, Volume 2. 767 pages. Taylor \& Francis CRC Press Book.

Rivadeneira, P.R., Agrelo, M., Otero, S. \& Kristoff, G. 2013. Different effects of subchronic exposure to low concentrations of the organophosphate insecticide chlorpyrifos in a freshwater gastropod. Ecotoxicol. Environ. Saf., 90: 82-88. doi:10.1016/j.ecoenv.2012.12.013

Rosen, J.E. 1997. Proposed mechanism for the photodynamic generation of 8-oxo-7,8-dihydro2'-deoxyguanosine produced in cultured cells by exposure to lomefloxacin. Mutat. Res., 381(1): 117-129. doi: 10.1016/S0027-5107(97)0015 9-0

Sarkar, A., Ray, D., Shrivastava, A.N. \& Sarker, S. 2006. Molecular Biomarkers: Their significance and application in marine pollution monitoring. Ecotoxicol., 15(4): 333-340. doi: 10.1007/s106 46-006-0069-1

Smith, P.T. \& Reddy, N. 2012. Application of magnetic resonance imaging (MRI) to study the anatomy and reproductive condition of live Sydney rock oyster, Saccostrea glomerata (Gould). Aquaculture, 334: 191-198. doi: 10.1016/j. aquaculture.2011.12.033

Tedoldi, D., Chebbo, G., Pierlot, D., Kovacs, Y. \& Gromaire, M.C. 2016. Impact of runoff infiltration on contaminant accumulation and transport in the soil/filter media of Sustainable Urban Drainage Systems: A literature review. Sci. Total Environ., 569-570: 904-926. doi: 10.1016/ j.scitotenv.2016.04.215

Trevigen. 2015. HT 8-oxo-dG ELISA Kit II. Retrieved from http://www.trevigen.com/product/5/24/ 0/8oxodG_ELISA_Kit_Antibodies/.

Volety, A. 2008. Effects of salinity, heavy metals and pesticides on health and physiology of oysters in the Caloosahatchee Estuary, Florida. Ecotoxicology, 17(7): 579-590. doi: 10.1007/s10646-008-0242-9

Wang, J., Wang, J., Zhu, L., Xie, H., Shao, B. \& Hou, X. 2014. The enzyme toxicity and genotoxicity of chlorpyrifos and its toxic metabolite TCP to zebrafish Danio rerio. Ecotoxicology, 23(10): 1858-1869. doi: 10.1007/s10646-014-1321-8

Webb, D. 2011. Freshwater shrimp (Palaemonetes australis ) as a potential bioindicator of crustacean health. Environ. Mon. Assess., 178(1): 537-544. doi: 10.1007/s10661-0101711-1

Wheelock, C.E., Eder, K.J., Werner, I., Huang, H., Jones, P.D., Brammell, B.F., Elskus, A.A. \& Hammock, B.D. 2005. Individual variability in esterase activity and CYP1A levels in Chinook salmon (Oncorhynchus tshawytscha) exposed to esfenvalerate and chlorpyrifos. Aquat. Toxicol., 74(2): 172-192. doi: 10.1016/j.aquatox.2005. 05.009 